\title{
БОРЬБА С НОСТАЛЬГИЕЙ КАК ПОЭТИЧЕСКИЙ ПРИЕМ В ПОЗДНЕЙ ЛИРИКЕ МАРИНЫ ЦВЕТАЕВОЙ
}

\author{
FIGHTING NOSTALGIA AS A DEVICE IN THE LATE POEMS \\ BY MARINA TSVETAEVA
}

\author{
РОМАН ВОЙТЕХОВИЧ
}

\begin{abstract}
Aвstract. Tsvetaeva spent seventeen years in exile and could not avoid the topic of nostalgia. However, her solution of the theme is polemical against the dominant tendencies in emigrant literature. Instead of aspiration to return to a concrete place, to the unchangeable organization of life (prerevolutionary Russia), she forges baroque-romantic type of nostalgia as a desire for eternal movement following a mobile target (after Charles Baudelaire).

Keywords: Tsvetaeva, emigrant literature, nostalgia, baroque-romantic style

Роман Войтехович, Тартуский университет, Тарту - Эстония, voitehh@mail.ru

ORCID ID: 0000-0003-0505-4537
\end{abstract}

Марина Цветаева была поэтом-лириком, автором лирических стихотворений, преимущественно до тридцати лет. В 1923 году ей исполнился тридцать один год, и поток малых лирических форм резко обмелел, а через три года совсем иссяк, возобновляясь позднее урывками; случались и годы молчания. Какое-то время это компенсировалось стихотворными драмами и поэмами, но и они постепенно отступили под натиском прозы.

Цветаева не хотела отказываться от малых форм лирики, буквально понукая свое вдохновение (ср. Разговор с Гением 1928 года и др.), но импульсов для лирических экспромтов становилось все меньше. Одним из последних и самых устойчивых стала тема ностальгии - общеэмигрантской тоски по родине. Теме ностальгии в творчестве русских писателей-эмигрантов посвящено немало работ российских исследователей [см. Помельникова 2013: 157-162; Пономарев 2016: 40-47; Серегина 2008: 169-175]. В последней работе отмечается, что это ностальгия была доминирующим чувством только у эмигрантов „первой волны“, что она связана не просто с отсуствием на родине, а с „невозможностью возвращения на родину“, и дается более обобщенное определение: „Ностальгия - это преодоление некоторого разрыва жизни... это всегда тоска, и часто острая и болезненная, по чему-то потерянному или утраченному" [Cе- 
регина 2008: 174-175]. Причем в цветаевском случае - это была и полемическая реакция на общее место эмигрантского дискурса. В упомянутом исследовании Татьяны Серегиной отмечается, что „эмигранты жаловались на отсутствие особого «воздуха» русской общественной жизни. Без него был невозможен процесс творчества" [Серегина 2008: 173]. Наверное, центральным текстом этой группы следует признать стихотворение Тоска по родине - давно... (1934), но к нему примыкают и многие другие лирические тексты этого времени, включая и большой цикл Стихи к Чехии (Чехия - „родина сына моего”), и стихи на отплытие из Франции Doucy France (1939).

Можно заметить, что и там, где нет разговора о родине, крае, речь у Цветаевой также идет преимущественно о ностальгии - по прошлому, по ушедшим близким, забывчивым возлюбленным и т.д. Складывается впечатление, что ностальгия - один из универсальных ключей к лирике Цветаевой (и даже к лирике в целом), причем не только в стихотворных текстах, но и в прозе. Ср.:

Цветаева была одним их тех поэтов, кто наиболее откровенно и прямолинейно пользовался в своем творчестве ностальгизмами, - с целью онтологической верификации своих поэтических конструкций... в ее стихах это способ постулировать бытие чего-либо, причем бытие именно истинное, подлинное... [Таратута 2017: 89-91].

Мемуарная и квази-мемуарная проза Цветаевой (прустианская по ориентации, как считает Ирина Шевеленко [2015: 342]) отчетливо питается энергией ностальгии - эмоциональной реакции на прошлое, на разлуку.

Цветаева вспоминает, что Максимилиан Волошин угадал ее характер: „Когда вы любите человека, вам всегда хочется, чтобы он ушел, чтобы о нем помечтать” [Цветаева 1995, IV: 165]. Действительно, Цветаева никогда бы не написала столько стихов к мужу (книга Лебединый стан, стихи 1917-1920 гг.), если бы не оказалась в разлуке с ним в период Гражданской войны: личные судьбы и судьбы страны переплелись до неразличимости. Получив известие о том, что он жив, она едет на встречу с ним в Берлин и там издает книгу Разлука (1922), название которой эхом отразилось еще в трех сборниках. Вдохновленный этим изданием Андрей Белый называет свой сборник После разлуки: берлинский песенник (1922). Цветаева же издает книгу с почти синонимичным названием После России (1928), куда войдут берлинские стихи („после России" - это и после разлуки с Россией). А спустя еще два года в далеком Харбине выйдет книга поклонника Цветаевой Арсения Несмелова Без России (1931). Ср.: 
Самым ярким “выразителем" ностальгической темы стал у Несмелова сборник с красноречивым названием Без России (Харбин, 1931). [...] Для поэта родина обусловлена, прежде всего, литературой: “Свою страну, страну судьбы лихой, / Я вспоминаю лишь литературно”. [...] Эти строки из первого стихотворения сборника станут его лейтмотивом... [Хадынская 2017: 185].

Так, ностальгия становится „перводвигателем" целой серии поэтических сборников, в которых ностальгия по человеку перерастает в ностальгию по стране: Разлука (1922) - После разлуки (1922) - После России (1928) - Без России (1931).

Ностальгия - следствие любви, ее осложненный вариант, включающий настоящее и прошлое, близкое и далекое. Для пишущего человека, апеллирующего к собственному опыту, рассказ о своих чувствах всегда частично локализован в прошлом, нередко - в другом пространстве. При этом в классическом варианте „тоска по родине” предполагает дистанцированное существование этой родины в настоящем, а, следовательно, и принципиальную возможность новой встречи с ней - в будущем. Суммируя, приходим к заключению, что ностальгический эффект может возникать:

а) при мыслях о будущем (контраст с печальным настоящим и ностальгическим прошлым);

б) при мыслях о настоящем (контраст с ностальгическим прошлым);

в) при мыслях о прекрасном прошлом (контраст с печальным настоящим).

Во всех трех случаях важен временной контраст и пространственная отделенность. Мечты о прекрасном будущем тоже могут быть окрашены в ностальгические тона, если переживается отделенность этого будущего от настоящего. Главное - элемент сожаления по поводу несовпадения актуальной реальности с потенциальной. Принципиальна не отнесенность объекта любви в прошлое, а разлученность с ним.

Изрядная доля лирики будет заведомо ностальгична, но, разумеется, не вся: ностальгия предполагает ощущение отделенности (маргинальности или внеположенности) авторской позиции по отношению к ценностному центру, она требует некой фрагментированости образа мира или даже двоемирия. Ощущение себя в „гуще событий” (даже угрожающих), восторг, радость, непосредственная реакция - все это входит в репертуар лирических эмоций иного рода. Один из признаков ностальгии - невозможность действия, прямого участия в какой-то иной жизни.

С эмблематической четкостью это выражено в классической миниатюре Генриха Гейне Ein Fichtenbaum steht einsam... (1827), известной во множестве переводов - Фета, Тютчева, но главным образом Лермонтова: 
На севере диком стоит одиноко

На голой вершине сосна

И дремлет качаясь, и снегом сыпучим

Одета, как ризой, она.

И снится ей всё, что в пустыне далекой -

В том крае, где солнца восход,

Одна и грустна на утесе горючем

Прекрасная пальма растет.

[Лермонтов 1979, I: 461]

Связь Цветаевой с темой стихотворения Гейне - Лермонтова прослеживается исследователями через мотив одиночества, тесно связанный с мотивом ностальгии:

С одной стороны, мы наблюдаем так называемое одиночество среди людей. Лермонтовский человек и миропорождающий субъект Цветаевой чувствуют себя... отличными от других. [...] Отказ от единения с другими служит верным доказательством... избранности, ...становится метафизической составляющей... поиском того края вселенной, где наконец-таки обрела бы покой их душа. И в доме - казалось бы, самом безопасном месте в мире - поэты отказывают себе в пристанище. [...] Образ дома у Лермонтова расширяется до размеров Вселенной, а в лирике Цветаевой - представляет собой третье пространство Словесности, ...зрелый лермонтовский человек стремится к успокоению и гармонии с Космосом, путь героини М. И. Цветаевой представляет собой непрекращающийся бег [Ситдикова 2008: 10-20].

Очевидно, что ель растет у себя на родине, что никакого предварительного опыта общения с пальмами у нее не было. О ностальгии в прямом смысле слова здесь не говорится. Но это - „обратная” ностальгия, инверсия ностальгии: тоска не по своему, а по чужому, экзотическому. Разнообразные аспекты мотивов „тоски” и „печали” в творчестве Цветаевой затрагивались в исследовательской литературе [см. Козакова 2009: 123-128; Старостина 2009: 298-303; Старостина 2010]. Однако, как мы увидим далее, в поэзии Цветаевой эта модель прекрасно работает и в рамках темы „тоски по родине”.

Странности описанной ситуации соотвествует общеромантическое стремление к нарушению стилистического единства: ель с пальмой явно не образуют внешне гармоничную пару (ср. романтическую интерпретацию любви Отелло и Дездемоны в Египетских ночах Александра Пушкина). В связи с этим вспоминается классическая дихотомия (вроде восточной инь-ян), впервые детально разработанная применительно к литературе именно в Польше: имеется в виду знаменитая синусоида стилей Юлиана Кшижановского, разграничивающего периоды рациональной и иррациональной ориентации искусства [см. Krzyżanowski 
1938]. Среди других дихотомичных концепций, восходящих к идеям Вёльфлина, Кшижановскому принадлежит приоритет: „В плане разработанности такой теории особое место занимает концепция Кшижановского. Ему же принадлежит и честь, и приоритет в истории литературоведения" [Чернов 1976: 124]. В рамках этой теории эпохи модернизма, романтизма, барокко и готики свидетельствуют о своеобразном кризисе нормативного восприятия действительности: нормы, разум ставятся под сомнение; „душа", подсознание высвобождается из пут здравого смысла и общей морали; происходит инвентаризация средств искусства и высвобождение духа художественного эксперимента в те области, где он традиционно сдерживался: проза звучит как стихи, архитектурные формы уподобляются жидким и растительным и т.д.

Все это подводит нас к одной типологической черте, отмеченной еще Генрихом Вёльфлином в 1888 г. в его книге Ренессанс и барокко [Wölfflin 1888] (на русском языке впервые опубликовано в 1913 г., переиздано в 2004 г.) и затем развитой в его основной работе Основные понятия истории искусства (1915) [Wölfflin 1915] (на русском языке впервые опубликовано в 1930 г., переиздано в 2002 г.). В рамках настоящего рассуждения мы бы изложили ее так: в искусстве типа барокко присуствует нечто вроде „ностальгии”. Преодолевая геометрическую ясность классицизма в архитектуре, барокко вносит объем и образную пластичность туда, где была только линия и плоскость. Фигуры наслаиваются друг на друга и прячутся за раму, возникают неясности, дали, глуби и выси. Взгляд притягивает бесконечность. Эта тяга за предел постижимого иногда оформляется как тоска души (гостьи этого мира) по небесному отечеству.

Характерно, что поворот к модернизму в русской литературе, обозначенный в манифесте Дмитрия Мережковского О причинах упадка и о новых течениях современной русской литературы (1892, публикация 1893):

Новейшая теория познания воздвигла несокрушимую плотину, которая навеки отделила твердую землю, доступную людям, от безграничного и темного океана, лежащего за пределами нашего познания. [...] ...Глыбы циклопической постройки... заложил Кант. [...] ...Ночь, из которой все мы вышли... более непроницаема, чем когда-либо. [...] Последний мистический луч потухает. [...] Мы свободны и одиноки!.. [...] Наше время должно определить двумя противоположными чертами: это время самого крайнего материализма и вместе с тем страстных идеальных порывов духа [Мережковский 2001; 34-35].

Этот абзац, характеризующий мистическую потребность человека эпохи Антона Чехова и Дмитрия Мережковского, хорошо передает комплекс ощущений, связанный не только с философско-религиозными пережи- 
ваниями, но и с характерным самоощущением любого выразителя духа барокко, романтизма, модернизма: мистическое чувство в этом аспекте выступает частным случаем проявления самодовлеющей „ностальгии”. Заметим, кстати, что и характерное бездействие в художественном мире Чехова известного своим неприятием мистики, имеет нередко ностальгический характер (ср. ностальгический образ „вишневого сада” и хрестоматийное стремление „В Москву!”).

Не всегда тоска влечет в запредельность, иногда „родиной души” оказывается другая страна или другая эпоха. Максимилиан Волошин чувствовал себя французом, а душой - эллином, Валерий Брюсов - римлянином эпохи Антонинов, но в своей поэзии перепробовал всё и даже побывал в космосе (С кометы, 1895). Ахматова сменила славянскую фамилию на татарскую фамилию бабушки и возводила себя к потомкам Чингисхана. Цветаева ощущала себя и цыганкой, и египтянкой, называла свою душу германской, а характер - польским. Характерно, что все это началось еще в эпоху романтизма, когда Лермонтов выбирал между Испанией и Шотландией, а Пушкин - между Африкой и Скандинавией („Под небом Африки моей...” - под стать еловым снам о пальмах). С этой точки зрения барочно-романтические следы самовосприятия наблюдаются уже у Гавриила Державина, который помнил о далеком предке - мурзе Багриме. Но показательно и значимое отсутствие „турецкого” мифа в саморепрезентации Василия Жуковского: имея настоящую мать-турчанку, поэт лишен возможности творить миф об экзотической „родине души”. Еще более парадоксальный пример дает биография Афанасия Фета с его германским происхождением и своеобразной „ностальгией" по отнятому у него праву считаться русским.

В романтизме и модернизме поэты часто „иностранцы” и даже „инопланетяне” (ср. цветаевское „Веги выходец”), поэтому и ностальгия у них парадоксальным образом направлена не на конкретное место свою страну, а на воображаемое, словно следуя поговорке „Хорошо там, где нас нет”. Не случайно, наверное, одной из последних крупных работ Цветаевой стал перевод Плаванъя Бодлера (Le Voyage, 1861), в котором описана бесконечная погоня за ускользающим „берегом” и покинутым „Раем":

В один ненастный день, в тоске нечеловечьей,

Не вынеся тягот, под скрежет якорей,

Мы всходим на корабль - и происходит встреча

Безмерности мечты с предельностью морей.

[...]

О, странная игра с подвижною мишенью!

Не будучи нигде, цель может быть - везде! 
Игра, где человек охотится за тенью,

За призраком ладьи на призрачной воде...

$[\ldots]$

Так старый пешеход, ночующий в канаве,

Вперяется в Мечту всей силою зрачка.

Достаточно ему, чтоб Рай увидеть въяве,

Мигающей свечи на вышке чердака

[Цветаева 1994, II: 396].

К тому моменту, когда Цветаева создавала свой перевод, она уже вернулась на Родину, в Москву, но, как мы знаем, это возвращение закончилось для нее трагедией. В эмиграции она создала целый ряд лирических текстов на тему родины, в основном - анти-ностальгических. Эти стихи - ответ на господствующие в ее семье настроения: все Эфроны рвутся в Россию. Даже маленький Мур повесил у себя над кроватью серп и молот из серебряной фольги.

В стихотворении Страна (1934) Цветаева заявляет: „Той России нету. / / - Как и той меня" [Цветаева 1994, II: 291]. Однако ностальгия прорывается. Свое двойственное чувство к родине Цветаева описала в стихотворении Бузина (1931-1935) через образ сада, заросшего бузиной, которая меняет цвет с зеленого на красный, а потом - на черный. У красной бузины „запекшейся крови вкус”, но героиня чувствует „нечто вроде преступной страсти” к ней, в том числе „и из-за слова” (а слово „бузить” значит буйствовать, бунтовать). Она надеется, что Россия, как и бузина, может преодолеть свою красную „корь”. Так Цветаева приучает себя к мысли о возвращении, хотя понимает, что в советской России, где только мертвый поэт может оказаться на своем месте (как в стихотворении о Волошине Ветхозаветная тишина..., 1932), ее поэзия не нужна. А главное, и в России ностальгия - тоска по родине - не иссякнет.

12 мая 1932 года Цветаева пишет стихотворение Родина:

О, неподатливый язык!

Чего бы попросту - мужик,

Пойми, певал и до меня:

- Россия, родина моя!

Но и с калужского холма

Мне открывалася она -

Даль - тридевятая земля!

Чужбина, родина моя!

Даль, прирождённая, как боль,

Настолько родина и столь -

Рок, что повсюду, через всю

Даль - всю её с собой несу! 
Даль, отдалившая мне близь,

Даль, говорящая: „Вернись

Домой!"

Со всех - до горних зве́зд -

Меня снимающая мест!

Недаром, голубей воды,

Я далью обдавала лбы.

Ты! Сей руки своей лишусь, Хоть двух! Губами подпишусь На плахе: распрь моих земля Гордыня, родина моя! [Цветаева 1994, II: 302]

Небесная Даль и высокая Гордыня - „родина“ поэта. В одном наброске А Бог с вами!.. (1934), написанном, видимо, под впечатлением от праздничной кинохроники, она сравнивает апологетов Гитлера и Сталина с овцами, которые составляют „из тел распластанных / Звезду или свасты крюки“ [Цветаева 1994, II: 316]. (В литературе не отмечалось, что использованная Цветаевой форма „сваста́” паронимически сближает понятие свастики со словом „звезда", образуя с ним пару по глухости-звонкости. Созвучие звезда-сваста́ подчеркивает глубинное сходство двух внешне оппозиционных „народных” режимов). Вот почему в 1934 году она утверждает: „Тоска по родине - давно / / Разоблаченная морока...“, то есть обман: Цветаева перечисляет все, чем соблазняет беженца тоска по родине, и все отвергает, даже тягу к родному языку: „мне безразлично, на каком непонимаемой быть встречным" [Цветаева 1994, II: 315-316]. Едва ли не каждый исследователь Цветаевой высказывался по поводу этого стихотворения, где „авторская попытка представить душевное состояние в виде давно достигнутого безразличия по отношению к отрицательным и положительным объектам оборачивается интенсивной эмоциональной реакцией" [Демченко 2017].

Но после развернутой градации, как это часто бывает в финале лирического стихотворения, происходит перелом с подразумеваемой антитезой [см. Войтехович 2013: 492-506]:

Так край меня не уберег

Мой, что и самый зоркий сыщик

Вдоль всей души, всей - поперек!

Родимого пятна не сыщет!

Всяк дом мне чужд, всяк храм мне пуст,

И все - равно, и все - едино.

Но если по дороге - куст

Встает, особенно - рябина... 
Приведенное возражение производит особенно сильное впечатление именно тем, что оно иррационально: вместо ряда доводов просто куст, который мгновенно превращается в дерево - рябину. Образ темный, непонятный и убедительный: тоска по Родине нахлынула с новой силой. И ее уже никакими доводами не остановишь.

Но подчеркнувшая переломом завершенность мнима, потому что антитеза заканчивается фигурой умолчания (апозиопезой), выраженной синтаксической незавершенностью и многоточием: все равно остается загадка, о какой родине идет речь? Почему рябина, а не береза, например? Россия рябины и бузины - это тот лик России, для которого Цветаева делает исключение. Он напоминает о Неопалимой купине, из которой Бог говорил с Моисеем, и о рябине, „горящей” в день Иоанна Богослова, когда Цветаева родилась. Но деревья не говорят по-русски, через них говорит Природа и Бог. Потом Цветаева возвращается к этой мысли в диптихе Куст. И опять родина оказывается ускользающей в бесконечность, а любое ее земное воплощение - только символом и подобием.

Так разговор о Родине в эмигрантской лирике Цветаевой становится способом в концентрированной форме выразить мироощущение художника эпохи модернизма.

\section{Библиография}

Белый А. 1922. После разлуки: Берлинский песенник, Петроград-Берлин: Эпоха.

Войтехович Р. 2010. Лирический ицикл «Куст» М. И. Цветаевой. II, „Вестник Православного Свято-Тихоновского Гуманитарного Университета", серия III, № 3 (21).

Войтехович Р. 2013. Верхнее «до»: градация в поэзии Цветаевой, [в:] А. А. Долинин (ред.), (Не) музыкальное приношение, или Allegro affettиово. Сборник статей к 65-летию Бориса Ароновича Каца, Санкт-Петербург: Издательство Европейского университета в Санкт-Петербурге.

ДемченкоЮ.2017.Языковыекомпонентыэмотивноститекстакакпоказательавторскогоотношения встихотворении М. И.Цветаевой «ТоскапоРодине», ,,StudiaHumanitatis", №3, электронный ресурс: http://st-hum.ru/content/demchenko-yuo-yazykovye-komponenty -emotivnosti-teksta-kak-pokazatel-avtorskogo-otnosheniya-v (доступ 1.01.2018).

Козакова А. 2009. Концепт «Печаль» в поэтическом идиолекте М. Цветаевой, „Известия высших учебных заведений", № 5 .

Лермонтов М. Ю. 1979-1981. Собрание сочинений: 84 m., Ленинград: Наука.

Мережковский Д. С. 2001. О причинах упадка и о новых течениях современной русской литературы, [в:] Н. Л. Бродский, Н. П. Судоров (сост.), Литературные манифесты: Оm символизма до „Октября”, Москва: Аграф.

Несмелов А. 1931. Без России, Харбин: Изд. Н. А. Гаммера.

Помельникова В. 2013. Идентичность русской эмиграции первой волны в Чехословакии через феномен ностальгии, „Культура. Духовность. Общество”, № 8. 
Пономарев Е. 2016. Кониепт «Отечество» в культурном сознании русской эмиграиии 1920-x годов, „Вестник Санкт-Петербургского государственного университета культуры и искусств", № 1 (26).

Пушкин А. С. 1978. Полное собрание сочинений: В 10 m., т. 6. Ленинград: Художественная проза.

Серегина Т. 2008. Феномен российской эмиграции начала ХХ века, „Ученые записки Таврического национального университета им. В. И. Вернадского", т. 21, № 3 (60).

Ситдикова Г. 2008. Мотив одиночества в лирике М. Ю. Лермонтова и М. И. Цветаевой, автореферат диссертации на соискание ученой степени кандидата филологических наук, Самара.

Старостина С. 2009. «Тоску раскуривать»: мотивный комплекс тоски по любимому в поэзии М. И. Цветаевой периода эмиграции, „Вестник Тамбовского университета”, № 6 (74).

Старостина С. 2010. Мотивное поле концепта «Тоска» в ^ирике М. И. Цветаевой периода эмиграции, автореферат диссертации на соискание ученой степени кандидата филологических наук, Тамбов.

Таратута Е. 2017. Ностальгический поиск подлинного: Борис Пастернак и Марина Цветаеba, „EINAI: Проблемы философии и теологии”, т. 6, № 1 (11).

Хадынская А. 2017. Утраченная Россия Арсения Несмелова. Материалы III Всероссийской научно-практической конферениии «Север России: стратегии и перспективы развития», Сургут: Сургутский государственный университет.

Цветаева М. И. 1994-1995. Собрание сочинений: 87 m., Москва: Эллис Лак.

Чернов И. 1976. Из лекиий по теоретическому литературоведению. I. Барокко. Литература. Литературоведение, Тарту: Тартуский государственный университет.

Шевеленко И. 2015. Литературный путь Цветаевой: Идеология, поэтика, идентичность автора $\mathrm{b}$ контексте эпохи, Москва: Новое литературное обозрение.

Krzyżanowski J. 1938. Od średniowiecza do baroku, Warszawa: Towarzystwo Wydawnicze Rój.

Wölfflin H. 1888. Renaissance und Barock: eine Untersuchung über Wesen und Entstehung des Barockstils in Italien, München: Theodor Ackermann Königlighter Hof. Buchhändler.

Wölfflin H. 1915. Kunstgeschichtliche Grundbegriffe: Das Problem der Stilentwicklung in der neueren Kunst, München: F. Bruckman A.-G. 